\title{
PENGEMBANGAN BAHAN AJAR INTERAKTIF BERBASIS MEDIA SOSIAL SCHOOLOGY
}

\section{DEVELOPMENT OF INTERACTIVE PHYSICS TEACHING MATERIALS BASED ON SOCIAL MEDIA SCHOOLOGY}

\author{
Sri Latifah ${ }^{1}$, Ardini Utami ${ }^{2}$ \\ ${ }^{1,2}$ Prodi Pendidikan Fisika Fakultas Tarbiyah dan Keguruan Universitas Islam Negeri Raden Intan \\ Lampung \\ E-mail: srilatifah@radenintan.ac.id
}

Diterima: 18 Januari 2019. Disetujui: 13 Februari 2019. Dipublikasikan: 29 Maret 2019

\begin{abstract}
This study aims:(1) to find out the feasibility of interactive physics teaching materials based on schoology social media, (2) to find out theresponse of students to the attractivenessinteractive physics teaching materials based on schoology social media that has been developed. This study is a Research andDevelopment $(R \& D)$ using Borg and Gall's procedure. This research was carried out at SMAYP UnilaBandar Lampung, SMA N1 Bukit Kemuning, andSMA N 7 Bandar Lampung with research objects were students of class XI. The results of the validation from material experts, media experts and technology experts showed very decent results with the presentations reaching $83.25 \%$. Then the teaching materials were tested through 2 steps, namely small trials and field trials. The average results obtained were 84,93\% for small group trials and $81.29 \%$ for field trials at SMA YP Unila Bandar Lampung, SMA N 1 Bukit Kemuning andSMA N 7 Bandar Lampung, so interactive physics teaching materials based on social media schoology from the three schools has very interesting criteria.
\end{abstract}

Keywords: e-learning, interactive teaching materials, schoology.

\begin{abstract}
Abstrak:Penelitian ini bertujuan untuk:(1) mengetahui kelayakan bahan ajar fisika interaktif berbasis media sosial schoology,(2) mengetahui respon peserta didik terhadap kemenarikan bahan ajar fisika interaktif berbasis media sosial schoology yang telah dikembangkan.Penelitian ini merupakan penelitian pengembangan atau Research and Development $(R \& D)$ dengan menggunakan prosedur Borg and Gall. Penelitian ini dilaksanakan di SMA YP Unila Bandar Lampung, SMA N 1 Bukit Kemuning, danSMA N 7 Bandar Lampung dengan objek penelitian adalah peserta didik kelas XI. Hasil validasi dari ahli materi, ahli media dan ahli teknologi menunjukkan hasil sangat layak dengan presentasi mencapai $83,25 \%$.Kemudian bahan ajar di uji coba melalui 2 tahap yaitu uji coba kecil dan uji coba lapangan. Hasil rata-rata yang diperoleh yaitu $84,93 \%$ untuk uji coba kelompok kecil dan $81,29 \%$ untuk uji coba lapangan di SMA YP Unila Bandar Lampung, SMA N 1 Bukit Kemuning dan SMA N 7 Bandar Lampung, sehingga bahan ajar fisika interaktif berbasis media sosial schoology dari ketiga sekolah tersebut memiliki kriteria sangat menarik.
\end{abstract}

(C) 2018 Unit Riset dan Publikasi Ilmiah FTK UIN Raden Intan Lampung

Kata kunci : e-learning, bahan ajar interaktif, schoology. 


\section{PENDAHULUAN}

Pesatnya perkembangan ilmu pengetahuan dan teknologi khususnya teknologi informasi dan komunikasi (TIK) memberikan pengaruh pada berbagai bidang kehidupan, termaksud bidangpendidikan. Apablia kita memahami peran teknologi maka kita semaksimal mungkin memanfaatkannya, demikian juga tantanganya, maka kita mempersiapkan diri terhadap tantangan tersebut(Yuberti, 2015) oleh karena itu tidak menutup kemungkinan bahwa guru dituntut lebih menguasai IPTEK untuk bersaing dengan dunia global, dengan mengikuti perubahan teknologi menggunakan media pembelajaran yang menarik dapat merangsang minat belajar peserta didik(Widyawati, 2003).

Fisika adalah ilmu pengetahuan yang mempelajari tentang kejadian alam dan keteraturannya. Fisika merupakan salah satu pelajaran yang kurang diminati, satu penyebabnya adalah fisika banyak mempunyai konsep yang bersifat abstrak(Dwi Aristya Putra, 2015; Mayub, 2005). Tujuan pembelajaran mata pelajaran fisika SMA yang adalah agar siswa menguasai konsep dan prinsip fisika untuk mengembangkan pengetahuan, keterampilan dan sikap percaya diri sehinga dapat diterapkan dalam kehidupan seharihari(Latifah, 2014). Sehingga yang perlu adanya pemahaman konsep bukan untuk dihapalkan, seharusnya guru membimbing peserta didik agar memiliki pengalaman langsung dalam pembelajaran yang berbasis teknologi informasi dan komunikasi.

Salah satu penerapan teknologi elektronik untuk pembelajaran yaitu $e$ learning berbasis belajar mandiri onlineuntuk menyampaikan pembelajaran teknologi berupa komputer, internet, serta teknologi elektronik lain seperti audio/radio, dan video/televisi (Prawiradilaga, 2016).Banyak sekali jenis e-learning, seperti moodle, edmodo, google classroom, schoology(Rohman, 2017).Elearning untuk siswa dalam pembelajaran harus menggunakan jenis yang mudah agar tidak mempersulit siswa.Salah satuelearning yang dikembangkan menggunakan aplikasi yaitu schoology.

Berdasarkan pra penelitian yang dilakukan di SMA YP UNILA Bandar Lampung, SMA N 1 Bukit Kemuning, SMA N 7 Bandar Lampung hasil pengamatan dikelas dalam proses pembelajaraan fisika yang berlangsung selama ini didominasi dengan media cetak (buku) maupun papan tulis, dan hanya sebagian guru yang menggunakan media power point yang didalamnya masih berisi tulisan dan gambar. Hal tersebut membuat suasana semakin tidak menarik mengakibatkan peserta didik jenuh kondisi seperti ini. Peneliti memilih ketiga sekolah ini dikarenakan fasilitas yang memungkinkan para guru fisika untuk melakukan pembelajaran fisika dengan menggunakan e-learning. Fasilitas yang tersedia adalah dan laboratorium komputer yang sudah terkoneksi dengan internet, oleh karena itu, fasilitas yang mampu meningkatkan proses pembelajaran sebaiknya dimanfaatkan secara optimal. Terlebih lagi peserta didik sudah terbiasa memanfaatkan internet dalam kehidupan sehari-hari.Pada penelitian ini berbeda dengan penelitian lainnya, peneliti mengembangkan bahan ajar fisika interaktif berbasis media sosial schoology, Schoology memiliki konsep yang sama dengan edmodo dan moodle, bahkan schoology memiliki beberapa fasilitas lain yang tidak didukung oleh edmodo dan moodle. Peneliti menginginkan suatu perubahan pembelajaran menggunakan bahan ajar nantinya akan menjadi panduan peserta didik untuk memperoleh pengetahuan tentang fisika. 
Berdasarkan uraian tersebut, maka peneliti akan melakukan suatu penelitian dengan judul "Pengembangan Bahan Ajar Interaktif Berbasis Media Sosial Schoology"

\section{LANDASAN TEORI}

\section{PengertianBahan Ajar Interaktif}

Bahan ajar interaktif adalah bahan ajar yang mengombinasikan beberapa media pembelajaran (audio, video, teks, atau grafik) yang bersifat interaktif untuk mengendalikan suatu perintah sehingga terjadi hubungan dua arah antara bahan ajar dengan penggunaanya(Prastowo, 2014).

Bahan ajar interaktif dibuat dengan teknologi multimedia. Penggunaan bahan ajar interaktif dengan teknologi multimedia dalam proses pembelajaran dapat meningkatkan efisiensi, motivasi, dan memfasilitasi belajar aktif,serta konsisten dengan belajar yang berpuat kepada peserta didik untuk belajar lebih baik.

\section{E-learning}

Kata e-learning terdiri dari dua bagian, yaitu e' yang merupakan singkatan dari 'electronica' dan 'learning' yang berarti 'pembelajaran'. Jadi e-learning berarti pembelajaran dengan mengunakan jasa bantuan perangkat elektronika(Warsita, 2008). E-learning yang diartikan sebagai materi pembelajaran atau pengalaman belajar yang disampaikan melalui teknologi elektronik. Jadi, dengan demikian dalam e-learning peserta didik tidak hanya belajar dari internet saja akan tetapi juga dari sumber lain seperti video dan audio(Sanjaya, 2012).

\section{Schoology}

Schoology adalah jejaring sosial berbasis web khusus (sekolah dan lembaga pendidikan tinggi) yang difokuskan pada kerjasama, untuk memungkinkan pengguna membuat, mengelola, dan saling berinteraksi serta berbagi konten akademis.

Kelebihan schoology :

Membentuk komunitas belajar untuk diskusi dan mengunggah tulisan blog

(2) Memberikan tugas dan memeriksa secara online. (3) Suport dengan berbagai pilihan file memantau ketepatan dan kehadiran peserta didik secara online.(4) Berbagai pilihan bentuk soal, pilihan ganda, jawaban benar atau salah, pilihan mengurutkan, dan essay.(5) Schoology dapat diintegrasikan dengan pelaporan dan informasi sekolah.(6) Mudah digunakan peserta didik untuk belajar mandiri ataupun kelompok.(7) Sebagai alternatif belajar yang menarik.(8) Membantu peserta didik dalam mengerjakan tugas dan secara online.(9)Dilengkapi dengan video dan gambar yang mendukung serta kegiatan dapat dilakukan oleh peserta didik berkelompok.(10) Penampilan fisik bahan ajar fisika interaktif berbasis media sosial schoology yang dikembangkan memiliki perpaduan warna yang menarik.

Adapun kekurangan schoology :

Membutuhkan akses internet.

Pengaturan bahasa yang belum mendukung Bahasa Indonesia.(3) Konten pada mobile phone kurang lengkap.(4) Membutuhkan waktu untuk selalu mengupdate schoology guru.

\section{METODE PENELITIAN}

Metode penelitian yang digunakan adalah metode Penelitian dan Pengembangan yang dikenal dengan istilah R\&D (Reseach and Development) dengan model Borg and Gall dengan menggunakan tujuh tahapan (Hidayat, Suyatna, \& Suana, 2017; Parmin \& Peniati, 2012; Setiawati, Maharta, \& Sesuna, 2011; Telaah, Aspek, $\&$ Arah, 2018). Menurut Sugiono metode penelitian dan pengembangan (Reseach and Development) yaitu metode penelitian yang 
digunakan untuk menghasilkan produk tertentu dan menguji keefektifan produk tersebut(Sugiono, 2016)

Dalam melakukan metode penelitian dan pengembangan (Reseach and Development) terdapat 10 (sepuluh) tahapan yaitu : potensi masalah, pengumpulan data, desain produk, validasi desain, revisi desain, uji coba produk, revisi produk, uji coba pemakaian, revisi produk dan produksi masal.Peneliti membatasi langkah-langkah penelitian dan pengembangan dari sepuluh mejadi tujuh langkah, dikarenakan pada langkah ke tujuh sudah menjawab rumusaan masalah dari peneliti.

Penelitian dimulai dari tahap pertama melakukan studi pendahuluan, pada tahap ini dilakukan analisis kebutuhan melalui observasi lapangan. Tahap kedua merencanakan produk, pada tahap ini melalui hasil studi pendahuluan digunakan untuk membuat perencanaan produk berupa desainschoology. Kemudian tahap ketiga mengembangkan produk bahan ajar interaktif schoology, dilanjutkan tahap keempat dengan validasi kepada ahli materi, ahli desain dan ahli teknologi.Tahap kelima revisi produk bahan ajar interaktif schoology, Selanjutnya tahap keenam uji coba produk dan tahap ketujuh revisi seletah melakukan uji coba produk.

Teknik pengumpulan dataialah menggunakan wawancara atau interview,observasi, dokumentasi. Instrumen pengumpulan data berupa angket, dengan menggunakan angket bahan ajarfisika interkatif berbasis media sosial schoology untuk menganalisis jawaban dari validator dan analisis respon peserta didik terhadap bahan ajarfisika interkatif berbasis media sosial schoology:

Dalam menentukan kelayakan bahan ajar fisika interkatif berbasis media sosial schoology, peneliti menggunakan penilaian sebagai berikut :
Tabel 1 Aturan Pemberian Skor (Sugiono

\begin{tabular}{ll}
\multicolumn{2}{c}{ 2018) } \\
\hline Kategori & Skor \\
\hline SB (Sangat Baik) & 5 \\
B (Baik) & 4 \\
C (Cukup) & 3 \\
K (Kurang) & 2 \\
SK (Sangat Kurang) & 1 \\
\hline
\end{tabular}

Skor dari setiap pernyataan untuk seluruh validator dirata-ratakan dan dinyatakan dalam bentuk persentase capaian dengan menggunakan persamaan (Asyhari \& Diani, 2017):

$$
\% S=\frac{\overline{S S}}{S_{m}} \times 100 \%
$$

Keterangan :

$$
\overline{S S}=\text { Skor rata-rata }
$$$$
S_{m}=\text { Skor Maksimal }
$$

Mengubah skor rata-rata yang diperoleh menjadi nilai kualitatif yang sesuai dengan criteria penilaian pada tabel 2 .

Tabel 2 skala kelayakan media pembelajaran (Sugiono,2017)

\begin{tabular}{lll}
\hline Kategori & Batasan & Bobot \\
\hline Sangat kurang layak & $20,01 \%-40 \%$ & 1 \\
Kurang layak & $20,01 \%-40 \%$ & 2 \\
Cukup layak & $40,01 \%-60 \%$ & 3 \\
Layak & $60,01 \%-80 \%$ & 4 \\
Sangat layak & $80,01 \%-100 \%$ & 5 \\
\hline
\end{tabular}

Dengan adanya tabel skala likert tersebut peneliti dapat melihat persentase hasil penilaian layak atau tidak produk untuk dijadikan sebagai bahan ajar fisika interaktif.

\section{HASIL DAN PEMBAHASAN}

A. Hasil Penelitian

Pengembangan bahan ajar fisika interaktif berbasis media sosial schoology,dimulai dari studi pendahuluan dengan observasi di tiga sekolah, hasil pengamatan dikelas guru sebagai pengajar menggunakan bahan ajar cetak dalam 
mengajarkan materi pengajaran khususnya pada mata pelajaran fisika.Kelemahan bahan ajar cetak kurang mampu untuk menampilkan beberapa materi menggunakan simulasi, sehingga peserta didik kesulitan memahami materi yang bersifat abstrak selain itu peserta didik menjadi bosan dan karena masih disajikan dengan analog. Data yang diperoleh bahwa sekolah tersebut belum terdapat bahan ajar fisika interaktif berbasis media sosial schoology. Peneliti melakukan analisis materi dalam pengembangan produk ini adalah materi alat-alat optik, pada materi ini banyak konsep yang berhubungan dengan kehidupan sehari-hari, yaitu menganalisis cara kerja alat-alat optik dan penerapannnya dalam kehidupan seharihari.

Pengembangan bahan ajar fisika interaktif berbasis media sosial schoology dengan peneliti sebagai instructor atau sebagai guru, dimulai dari mendesain dengan memanfaatkan fitur courses untuk memasukan materi fisika yang dikembangkan. Membuat sebuah folder yang terdiri dari petunjuk schoology, handout materi, latihan soal dan uji kemenarikan.Handout materi terdiri pengayaan yang dilengkapi video pembelajaran dan simulasi, pada handout materi pokok maupun pengayaan dilengkapi dengan contoh soal dengan penyesaianya dan juga fokum diskusi.

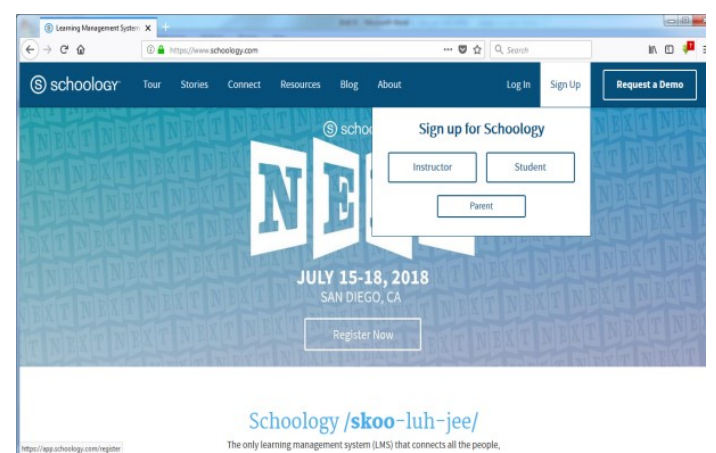

Gambar 1.http://schoology.com.

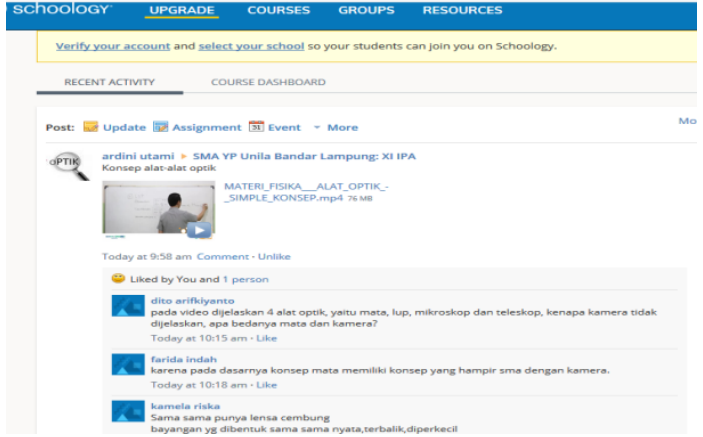

Gambar 2. Tampilan schoologysetelah Log in.

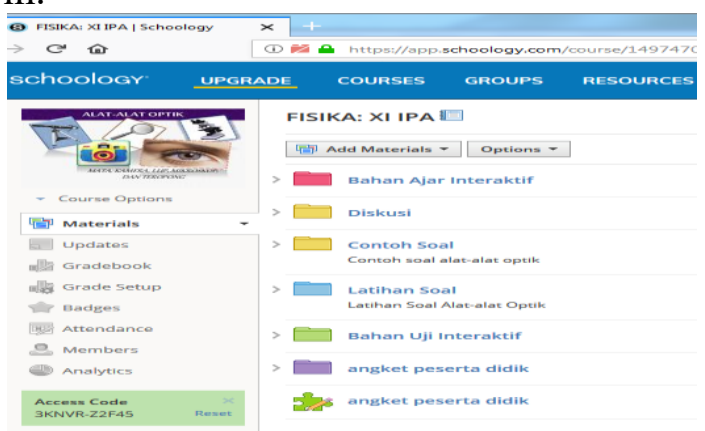

Gambar 3. Tampilan coursesschoology alatalat optik.

Video dan simulasi pembelajaran ditambahkan melalui fitur addfile/link. Soal diskusi dibuat menggunakan fitur discussion, yang dilengkapi dengan gambar dan juga video.Selanjutnya untuk latihan soal dan uji kemenarikan dikembangkan dengan fitur test/quiz.Soal latihan dan uji kompetensi dikembangkan dalam bentuk pilihan jamak, jawaban benar atau salah yang disertai umpan balik pada setiap jawaban.Statistik nilai hasil latihan dapat dilihat pada fitur gradebook.

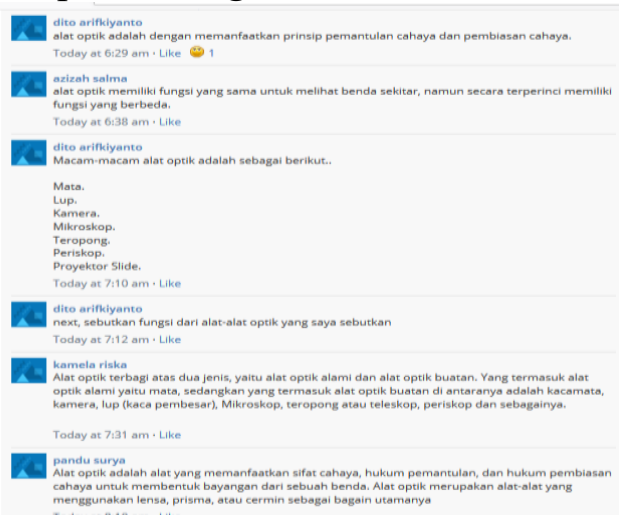

Gambar 4.Tampilan diskusi peserta didik. 


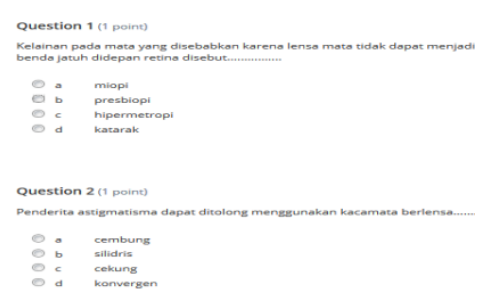

Gambar 5.Peserta didik menjawab soal latihan.

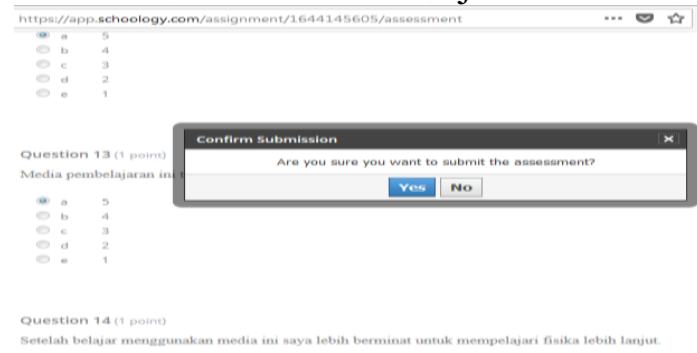

Gambar 6.umpan balik schoology pada setiap jawaban.

Peneliti melakukan validasi kepada tiga validator sesuai bidang ahli untuk mengetahui tingkat kelayakan bahan ajar interaktif yang akan digunakan untuk penelitian.Uji kelayakan produk dilakukan dengan memberikan instrument penilaian berupa angket yang dinilai menggunakan skala Likert 1-5.Berdasarkan total persentase keidealan tiap validasi ahli materi, ahli media, ahli teknologi dan respon guru terdapat pada tabel 3

Tabel 3 Hasil Keseluruhan Validasi

\begin{tabular}{lll}
\hline No & Aspek & Persentase (\%) \\
\hline 1 & Materi & $82,26 \%$ \\
2 & Media & $83,75 \%$ \\
3 & Teknologi & $83,75 \%$ \\
4 & Guru & $83,64 \%$ \\
\hline
\end{tabular}

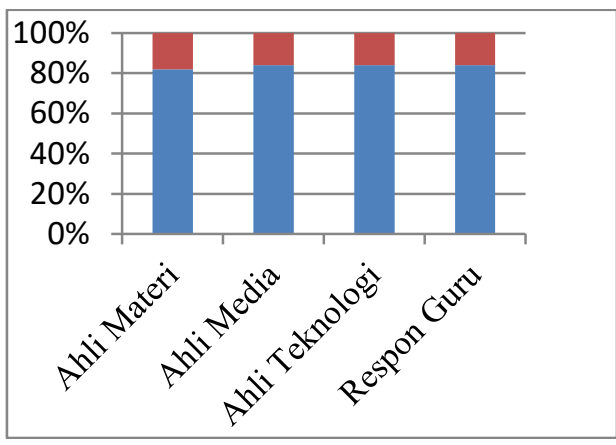

Gambar 7.Grafik Keseluruhan Validasi

Berdasarkan grafik diatas didapatkan bahwa pada ahli materi $82,26 \%$ adalah dalam kategori sangat layak. Pada ahli media $83,75 \%$ adalah dalam kategori sangat layak. Pada ahli teknologi $83,75 \%$ adalah dalam kategori sangat layak. Danrespon guru adalah $83,64 \%$ dalam kategori sangat layak. Sehingga bahan ajar fisika interaktif berbasis media sosial schoology dalam kategori sangat layak.

Tabel 4Hasil Uji Coba Lapangan

\begin{tabular}{lll}
\hline No & Institusi & $\begin{array}{l}\text { Persentase } \\
(\%)\end{array}$ \\
\hline 1 & SMA YP Unila B.Lampung & $87,23 \%$ \\
2 & SMA N 1 Bukit Kemuning & $75,42 \%$ \\
3 & SMA N 7 Bandar Lampung & $81,23 \%$ \\
\multicolumn{2}{l}{ Total Aspek } & $81,30 \%$ \\
\hline
\end{tabular}

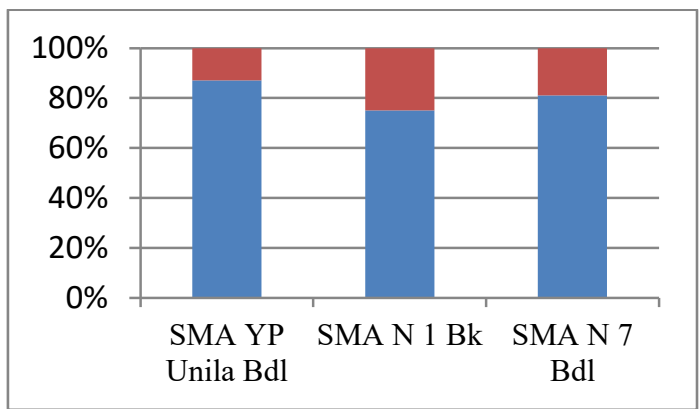

Gambar 8.Grafik Uji Coba Lapangan

Berdasarkan grafik pada uji coba lapangan yang merupakan uji coba keefektivan tahap akhir pada pengembangaan produk, didapatkan 
persentase hasil pada uji coba lapangan pada ketiga sekolah yaitu sebesar $87,23 \%$, $75,42 \%$ dan $81,23 \%$ sehingga persentase total ketiga sekolah tersebut didapatkan rata-rata persentase sebesar $81,30 \%$ dan pengembangan bahan ajar fisika interaktif berbasis media sosial schoology sangat layak digunakan sebagai sumber belajar.

\section{B. Pembahasan}

Penelitian ini bertujuan untuk mengetahui kelayakan dan kemenarikan bahan ajar fisika interaktif berbasis media sosial schoology materi alat-alat optik.Untuk untuk mengetahui kelayakan dan kemenarikan bahan ajar fisika interaktif berbasis media sosial schoology yang dikembangkan, maka peneliti menggunakan prosedur penelitian pengembangan Borg and Gall.

Hasil validasi dilakukan oleh ahli materi, ahli media, ahli teknologi dan respon guru yaitu guru fisika SMA YP Unila Bandar Lampung, SMA N 1 Bukit Kemuning, SMA N 7 Bandar Lampung.Hasil penilaian pada ahli materipersentase rata-rata mencapai 82,26\% kriteria interpretasi "Sangat Layak", selanjutnya melakukan vaidasi ahli media dengan persentase ratarata mencapai $83,75 \%$ kriteria interpretasi "Sangat Layak", dan melakukan validasi ahli teknologi hasil penilaian validasi teknologi sebesar $83,75 \%$, selanjutnya dilakukan oleh respon guru (penilai) yaitu guru fisika SMA YP Unila Bandar Lampung, SMA N 1 Bukit Kemuning, SMA N 7 Bandar Lampung berdasarkan hasil rekapitulasi nilai bahwa persentase rata-rata pada validasi guru/praktisi mencapai $83,64 \%$ dengan kriteria sangat layak.

Penelitian yang dilakukan diuji cobakan melalui dua tahap yaitu uji kelompok kecil dan uji coba lapangan. Hasil rata-rata kemenarikan yang diperoleh yaitu $84,93 \%$ untuk uji coba terbatas dan $81,30 \%$ untuk uji coba luas dari ketiga sekolah, ini berarti bahan ajar fisika interaktif yang dikembangkan dalam kriteria interpretasi kemenarikan sangat layak. Hasil dari perbaikan bahan ajar fisika interaktif bebasis media sosial schoology adalah produk akhir yang siap digunakan oleh peserta didik maupun guru dalam proses pembelajaran.

Bahan ajar fisika interaktif berbasis media sosial schoology, sesuai dengan namanya yaitu interaktif, dua komunikasi yang saling aktif, ketika peserta didik mengaplikasikan program ini, peserta didik diajak untuk terlibat secara aktif, auditif, visual, dan kinetik. Interaktifnya peserta didik dapat dilihat dari forum diskusi yang melatih peserta didik untuk menyampaikan pendapat atau komentar serta berbagai informasi untuk menyelesaikan pertanyaan atau diskusi, dan pada schoology terdapat soal latihan yang dapat diakses oleh peserta didik untuk melatih pengetahuan, dimana terdapat umpat balik (feedback) yang langsung diketahui oleh peserta didik selesai mengerjakan soal tersebut.

Schoologymemiliki konsep yang sama dengan edmodo (LMS + Social Networking), dan mendukung hampir semua fasilitas yang didukung oleh edmodo. Bahkan schoology memiliki beberapa fasilitas lain yang tidak didukung oleh edmodo, bahkan oleh moodle.Jika pada edmodo anda mengenal library, maka pada schoology, library serupa dengan add materials. Berikut tampilannya: 


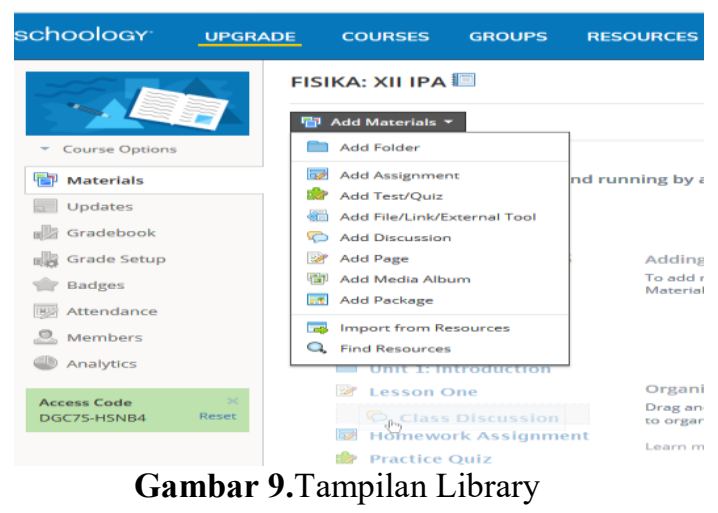

Seperti yang terlihat pada gambar di atas, spesifikasi schoology menyediakan lebih banyak pilihan add materials atau editor (penyuting yang sangat lengkap) dari pada yang disediakan oleh edmodo. Schoology juga bisa menampung jenis soal (question bank) yang akan digunakan pada Quiz.

Kelebihan lain schoology dari edmodo adalah tersedianya fasilitas attandance/absensi, dan juga fasilitas analityc (tidak disupport oleh moodle) melalui fitur analytic ini, bisa melihat di mana saja atau pada aktivitas apa saja peserta didik biasa menghabiskan waktu mereka ketika peserta didik login. Jika pada edmodo tidak ada fasilitas secara khusus untuk berkirim surat/message dan hanya melalui direct post, maka pada schoologybisa berkirim surat kemanapun melalui fasilitas messages yang tersedia, tidak hanya bisa meng-update status schoology untuk course atau group anda saja, melainkan juga bisa mengintegrasikan (sharing) postingan anda ke account facebook atau twitter.

Schoologymemiliki fasilitas yang lebih lengkap yang tidak didukung olehedmodo, bahkan oleh moodle Schoologydiaksessecara online sehingga dapat langsung diakses kapan pun dan dimana pun pada komputer atau laptop serta smartphone manapun yang terkoneksi internet dan memiliki aplikasi web browser (seperti Opera, Mozila Firefox, Goofle Chrome dan lain-lain). Produk hasil pengembangan dapat digunakan sebagai pembelajaran bagi peserta didik, baik secara mandiri ataupun berkelompok

Adapun kelebihan dan kekurangan bahan ajar fisika interaktif bebasis media sosial schoology antara lain :

\section{Kelebihan}

a. Mudah digunakan peserta didik untuk belajar mandiri ataupun kelompok.

b. Sebagai alternatif belajar yang menarik.

c. Dilengkapi dengan video dan gambar yang mendukung materi alat-alat optik serta kegiatan yang dapat dilakukan oleh peserta didik berkelompok.

d. Membantu peserta didik dalam mengerjakan tugas dan secara online.

e. Bahan ajar fisika interaktif berbasis media sosial schoology juga menyediakan fasilitas untuk mengelola nilai (grade) hasil quiz atau aktivitas lainnya via Gradebook.

f. Menyediakan fasilitas Analityc, melalui fitur analytic ini bisa melihat di mana saja atau pada aktivitas apa saja seorang peserta didik biasa menghabiskan waktu mereka ketika peserta didik login.

g. Schoology bisa berkirim surat kemanapun melalui fasilitas Messages yang tersedia.

h. Tidak hanya bisa meng-update status Schoology untuk course atau group saja, melainkan anda juga bisa mengintegrasikan (sharing) postingan ke account Facebook atau Twitter.

i. Penampilan fisik bahan ajar fisika interaktif berbasis media sosial 
schoology yang dikembangkan memiliki perpaduan warna yang menarik.

\section{Kelemahan}

a. Bahan ajar fisika interaktif berbasis media sosial schoology yang dikembangkan hanya pada sub pokok bahasan pada materi alat-alat optik.

b. Peneliti masih merasa produk ini masih banyak kekurangan, karena sedikitnya literatur dan pengetahuan terbatas.

c. Pengaturan bahasa yang kurang variatif, belum mendukung Bahasa Indonesia.

d. Produk ini tidak dapat digunakan pada sekolah-sekolah dan khususnya peserta didik yang belum memiliki fasilitas teknologi dan informasi dan komunikasi yang memadai, karena produk bahan ajar fisika interaktif berbasis media sosial schoology ini hanya dapat diakses secara online.

\section{SIMPULAN DAN SARAN}

\section{A. Simpulan}

Kelayakan produk bahan ajar interaktif berbasis media sosial schoology berdasarkan hasil validasi ahli materi didapatkan persentase sebesar $82,26 \%$ dengan kriteria "Sangat Layak", ahli media dengan persentase sebesar $83,75 \%$ dengan kriteria "Sangat Layak", ahli teknologi dengan persentase sebesar $83,75 \%$ dengan kriteria "Sangat Layak", dan respon guru dengan persentase sebesar $83,64 \%$ dengan krteria "Sangat Layak", sehingga bahan ajar fisika interaktif berbasis media sosial schoology sangat layak digunakan pada proses pembelajaran.

\section{B. Saran}

Dari hasil penelitian, analisis, pembahasan dan kesimpulan dapat dikemukakan beberapa saran sebagai berikut:

1. Pembelajaran mengunakan bahan ajar fisika interaktif berbasis media sosial schoology dapat dikembangkan oleh guru secara berkelanjutan untuk mata pelajaran dan materi yang berbeda.

2. Mengujicobakan kegiatan pembelajaran menggunakan bahan ajar fisika interaktif berbasis media sosial schoology pada subjek penelitian yang berbeda.

3. Dalam pembuatan bahan ajar fisika interaktif berbasis media sosial schoology terdapat beberapa kendala atau kesulitan yang mungkin bisamenjadi perbaikan bagi peneliti yang lain untuk mengembangkan bahan ajar fisika interaktif berbasis media sosial schoology dengan materi lain dianteranya: memperhatikan pemilihan kata dan konsep yang tepat, memperbanyak video pembelajaran dan evaluasi soal yang menarik.

\section{DAFTAR PUSTAKA}

Asyhari, A., \& Diani, R. (2017). Pembelajaran Fisika Berbasis Web Enhanced Course: Mengembangkan Web-Logs Pembelajaran Fisika Dasar I. Jurnal Inovasi Teknologi Pendidikan, 4(1).

Dwi Aristya Putra, P. (2015). Real Life Video Evaluation Dengan Sistem ELearning Untuk Meningkatkan Keterampilan Berpikir Krits Mahasiswa Fisika. 6(1), 69-77. https://doi.org/10.21831/JK.V45I1.718 7

Hidayat, A., Suyatna, A., \& Suana, W. 
(2017). Pengembangan Buku Elektronik Interaktif Pada Materi Fisika Kuantum Kelas Xii Sma. Jurnal Pendidikan Fisika, 05(02), 87-101.

Latifah, S. (2014). Implementasi Pembelajaran Bervisi SETS disekolah. Jurnal Ilmiah Pendidikan Fisika AlBiruni, 3(1), 2.

Mayub, A. (2005). E-Learning Fisika Berbasiskan Macromedia Flash M. Yogyakarta: Graha Ilmu.

Parmin, \& Peniati, E. (2012). Pengembangan Modul Mata Kuliah Strategi Belajar Mengajar IPA berbasis Hasil Penelitian Pembelajaran. Jurnal Pendidikan IPA Indonesia, 1(1), 8-15.

Prastowo, A. (2014). Pengembangan Bahan Ajar Tematik. Jakarta: Kencana.

Prawiradilaga, D. S. (2016). Mozaik Teknologi Pendidikan. Jakarta: Kencana.

Rohman, M. F. (2017). Learning Management System SCHOOLOGY. Bojonegoro: Pustaka Intermedia.

Sanjaya, W. (2012). Media Komunikasi Pembelajaran. jakarta: Prenadamedia.

Setiawati, D., Maharta, N., \& Sesuna, F. (2011). Pengembangan Media Interaktif Berbasis Teknologi, Informasi, dan Komunikasi pada Materi Kemagnetan. (1), 61-71.

Sugiono. (2016). metode Penelitian Kuantitatif Kualitatif dan RnD. bandung: alfabet.

Telaah, I., Aspek, K., \& Arah, D. A. N. (2018). Industri 4.0: telaah klasifikasi aspek dan arah perkembangan riset. 13(1), 17-26.

Warsita, B. (2008). Teknologi Pembelajaran Landasan \&Aplikasinya. Jakarta: Rineka Cipta.

Widyawati, N. S. (2003). Pengembangan Elearning Dengan Menggunakan Media Schoology Untuk Meningkatkan Hasil Belajar Siswa Pada Mata Pelajaran
Jaringan Dasar Kelas X TKJ di SMKN 3 Jombang. Jurnal IT-Edu, O1(01), 124.

Yuberti, Y. (2015). Online Group Discussion pada Mata Kuliah Teknologi Pembelajaran Fisika. Jurnal Ilmiah Pendidikan Fisika Al-Biruni, 4(2). 